\title{
Multipath Forecasting: the Aftermath of the 2020 American Crisis
}

Peter Turchin

Complexity Science Hub Vienna

March 5, 2021

\section{Abstract}

Recent years have seen major political crises throughout the world. Most recently, the US was swept by a wave of protests, urban riots, and violent confrontations between left- and right-wing extremists. Understanding how future crises will unfold and assessing the resilience of different countries to various shocks is of foremost importance in averting the human costs of state breakdown and civil war. In a recent publication (Turchin et al. 2018) we proposed a novel transdisciplinary approach to modeling social breakdown, recovery, and resilience. This approach builds on recent breakthroughs in macrosocial dynamics (and specifically structural-demographic theory), statistical analysis of large-scale historical data, and dynamic modelling. Our main goal is to construct a series of probabilistic scenarios of social breakdown and recovery. We called this approach-similar to ensemble forecasting in weather prediction-multipath forecasting (MPF). In this article I develop a "prototype" of the MPF engine with the goal of illustrating the utility a fully developed version may have. I first apply the computational model to the period of American history from the beginning of the nineteenth to the end of the twentieth century, with the goal of parameterizing the model and testing it against data. Then I use the parameterized model to forecast the dynamics of instability in the USA beyond 2020 and illustrate how the MPF engine can be used to explore the effects of different policy interventions.

\section{Introduction}

Collapse of historical states, empires, and whole civilizations is the subject of an enormous body of literature (for reviews see Tainter 1988, 1995, Diamond 2004, Butzer and Endfield 2012, Casti 2012, Cumming and Peterson 2017). Collapse is defined in various ways by different authors and disciplines (Cumming and Peterson 2017). Its various dimensions include rapid loss of social complexity (Tainter 1988), loss of centralized administration (Renfrew 1984), a drastic decrease in human population numbers (Diamond 2004), and even regional abandonment (Weiss and Bradley 2001).

Collapse, however defined, is a possible end result of social systems entering periods of falling resilience and heightened socio-political instability (collapse can also happen as a result of exogeous forces, such as a devastating invasion or a pandemic, but the focus of this article is on the internal causes). Historical analysis indicates that all complex societies organized as states experience such recurrent instability periods, or "Ages of Discord" (Turchin 2016). However, while entry into an Age of Discord is fairly stereotypical (see next section), exiting it can result in a broad fan of possibilities, ranging from deep collapse, at one extreme, to mild instability resolved by the elites and population pulling together to adopt the necessary reforms, at the opposite extreme.

There is now (as of February 2021, when this article was written) a broad acceptance by all parties that the United States has entered an Age of Discord. I analyzed the structural trends and social forces for instability that are currently spiking in a book published five years ago (Turchin 2016). Now that we are in crisis, the main question becomes, which route will our society take, and where will it fall in the fan of possibilities?

This article builds on previous collaborative research with Sergey Gavrilets, James Bennett, Daniel Hoyer, and the Vienna workshop on Social Complexity and Collapse (Turchin et al. 2018). I describe a computational model for projecting forward the dynamics of socio-political instability in the 
United States beyond 2020 under various scenarios. Because I am interested in exploring how various interventions can affect the future trajectories, I will call this model the "MPF engine," where MPF stands for MultiPath Forecasting (Turchin et al. 2018).

The proposed MPF engine is a lightly modified version of the model that I had previously used to make the prediction that the USA would experience an instability spike during the 2020s. This prediction was published in February 2010 (Turchin 2010), and the model details were elaborated in subsequent publications (Turchin 2013, 2016). As a caveat, the current version of the MPF engine is not a fully developed product, but merely a "prototype" that I use to illustrate the promise of the MPF approach.

This article is organized as follows. First, I give an overview of the structural-demographic theory, which provides the theoretical framework for the MPF model. Next, I review the data patterns that are most relevant to developing a predictive approach. The following section describes the computational model underlying the MPF engine. Next, I apply the model to the period of American history from the beginning of the nineteenth to the end of the twentieth century, with the goal of parameterizing the model and testing it against data. The final section (before the Conclusion) uses the parameterized model to forecast the dynamics of instability in the USA beyond 2020 and illustrates how MPF can be used to explore the effects of policy interventions.

\section{Structural-Demographic Theory as the Modeling Framework}

Historical research indicates that the dynamics of sociopolitical instability in complex societies organized as states are not purely random (Turchin et al. 2018). History is not just "one damned thing after another," as Arnold Toynbee famously said in response to another historian (Toynbee 1957: 267). There is a regular, albeit dynamically complex, pattern involving at least two cycles superimposed on each other (plus exogenous stochasticity on top of that). First, there are long-term waves of political instability periods with durations of a century or more (these are Ages of Discord) that are interspersed with relatively stable periods. Second, there is a shorter oscillation with an average period of c.50 years.

Structural-demographic theory (SDT) offers an integrative framework for investigating the multiple interacting forces shaping the long-term social pressures that lead to revolutions, civil wars, and other major outbreaks of sociopolitical instability (Goldstone 1991, Turchin 2003, Korotayev and Khaltourina 2006, Turchin and Nefedov 2009). Furthermore, SDT can be, and has been, formulated as an explicit computational model capable of forecasting future quantitative dynamics of social unrest and political violence in specific social systems (Turchin 2010, 2013, 2016).

According to SDT, the causes of revolutions and major rebellions are in many ways similar to the processes that cause earthquakes (Goldstone 1991: 35). In the study of both revolutions and earthquakes it is useful to distinguish "pressures" (structural conditions, which build up slowly) from "triggers" (sudden releasing events, which immediately precede a social or geological eruption). Specific triggers of political upheavals, like the self-immolation of Mohamed Bouazizi, which sparked the Arab Spring, are difficult, perhaps even impossible, to predict. On the other hand, structural pressures build up slowly and more predictably, and are amenable to analysis and forecasting. Further, many triggering events themselves are ultimately caused by pent-up social pressures that seek an outlet-in other words, by the structural factors. More importantly, the consequences of the triggering event are heavily mediated through the underlying context, namely these structural conditions. The self-immolation of Norman Morrison protesting US involvement in the Vietnam War, for instance, had a very different impact from that of Mohamed Bouazizi due to the divergent structural conditions.

The main focus of SDT is on the structural pressures undermining social resilience. The theory represents complex human societies as systems with three main compartments (the general population, the elites, and the state) interacting with each other and with sociopolitical instability via a web of 
nonlinear feedbacks (see Turchin 2013, 2016). Over the past four decades SDT has proven adept not only at explaining the dynamics of crisis, resilience, and recovery in a number of historical cases ranging from ancient empires to early modern states and nineteenth-century revolutions and civil wars (Goldstone 1991, Nefedov 2002, Turchin 2003, 2005, Korotayev and Khaltourina 2006, 2009, 2009, 2011, 2012, 2016), but also at predicting upcoming waves of violence and instability. In 2010 I used SDT to make the following forecast: "The next decade is likely to be a period of growing instability in the United States and western Europe" (Turchin 2010). This prediction was not simply a projection of the contemporary (in 2010) trend of social instability into the future-instability in Western countries had been, in fact, declining prior to 2010 (Figure 1). Rather, the basis for this forecast was a model that quantified structural drivers for sociopolitical instability, such as stagnating/declining real wages, a growing gap between rich and poor, overproduction of young graduates with advanced degrees, increasing public debt, and declining confidence in state institutions. This model highlighted 2020 as the year of spiking instability, a prediction that has unfortunately proven devastatingly accurate.

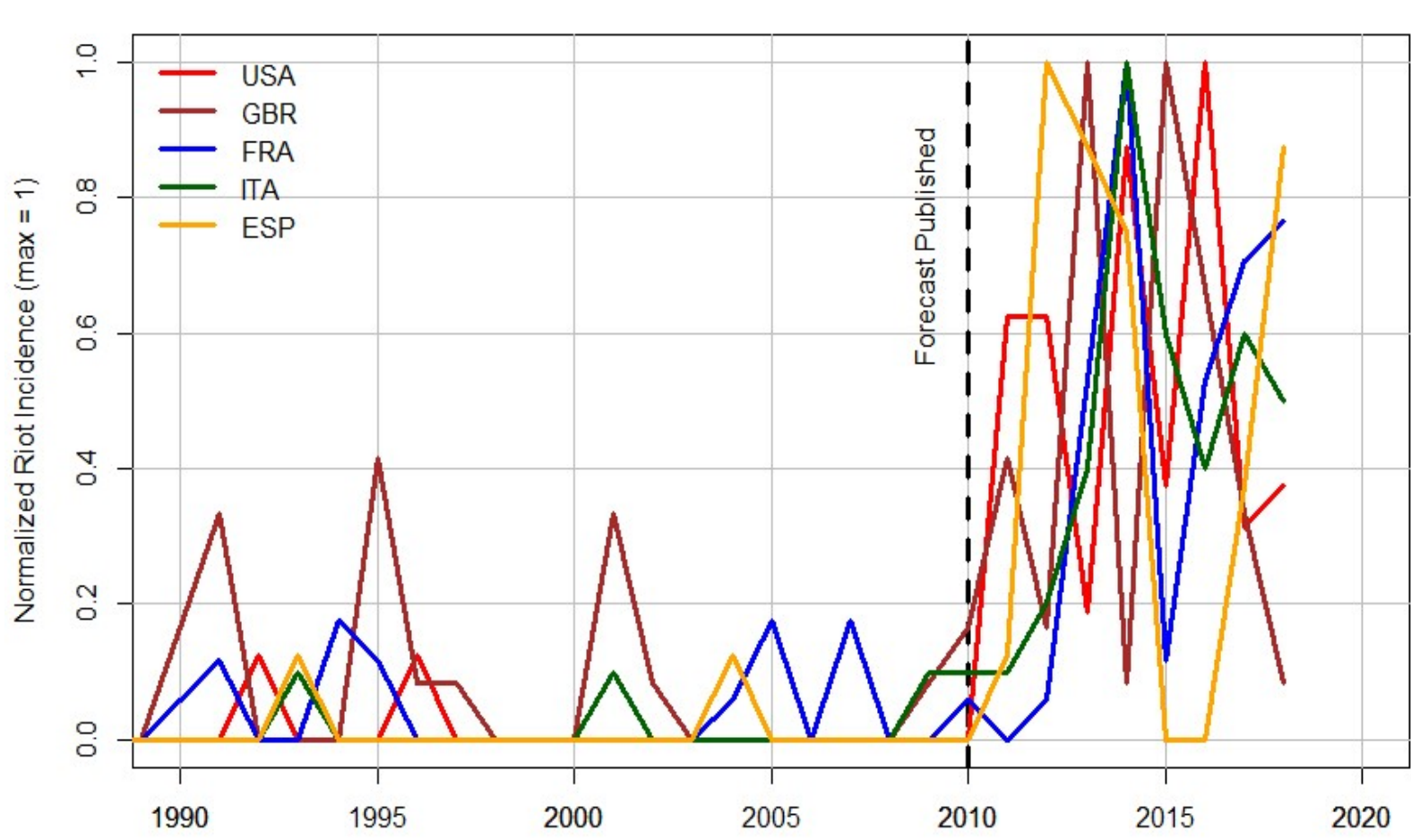

Figure 1: Temporal trends of violent riot incidence in five Western countries (Turchin and Korotayev 2020).

\section{Data Patterns}

The goal of the MPF approach is to first explain and then forecast the dynamics of socio-political instability (which is, therefore, the response variable). The computational model uses a variety of inputs to enable such forecasting (these inputs are, thus, predictor variables). In this section I review the various proxies that allow us to quantify both response and predictors. 


\section{Response Variable: Socio-Political Instability}

Political instability is violent group-level conflict within a state. It occupies the middle ground between interstate warfare and individual violence/crime. Instability events vary in scale from an intense and prolonged civil war claiming thousands (sometimes even millions) of human lives to a one-day urban riot with a handful of deaths, or even a violent demonstration with none. However, when studying instability in past and contemporary societies our primary focus is on lethal events, those that have caused loss of life. Such a conservative approach, while excluding a number of legitimate instability events, has two advantages. First, it clearly demarcates political violence from peaceful demonstrations and non-violent labor strikes. Second, and even more important, events that involve loss of life are much more likely to be reported in the media. Thus, focusing on lethal events reduces the effect of various reporting biases and allows us more faithfully to reconstruct the temporal dynamics of political violence.

Turchin (2012) describes a computerized database on the dynamics of sociopolitical instability in the US between 1780 and 2010. This US Political Violence (USPV) database includes 1590 political violence events such as riots, lynchings, and terrorism. Incidents of political violence in USPV database are classified by whether both opposing sides are substantial groups of people (specifically, more than 12 individuals), or whether one side is a group, and the other is one or few (under 12) individuals. The boundary of 12 between "few" and "many" is arbitrary: it simply follows the precedent established by Gilje (1996).

The generic term for group-on-group violence used both in scientific literature (Gilje 1996, Grimstead 1998) and in American newspaper reports is riot. Gilje defines a riot as "any group of 12 or more people attempting to assert their will immediately through the use of force outside the normal bounds of law" (Gilje 1996:4). Turchin (2012) modified this basic definition by distinguishing between group-on-group violence (proper riots) and group-on-individual violence (termed lynchings). If a riot is a conflict between groups of people, a lynching is lethal violence perpetrated by many on one or a few individuals. Violence perpetrated by one/few on many includes, first, terrorism, which is generally directed against some social or political institution, or society as a whole. A second important class is assassination, that is, when an individual is targeted not as a private person, but as a representative or an embodiment of some social group or political institution. The third category is indiscriminate mass murder, in America most often taking the form of shooting rampages. This is a relatively new type of violence that has become common in the US only in the past three or four decades. Although they give the appearance of senseless, random violence because the great majority of shooting rampages do not target specific individuals, I treat indiscriminate mass murder as a form of terrorism-suicide terrorismbecause the only difference between a rampage shooter and a suicide bomber is in the weapon used to inflict damage (in fact, indiscriminate mass murderers use not only guns, but knives, vehicles, and explosives). Both aim not at individual people but at groups, social or political institutions, or entire societies. 


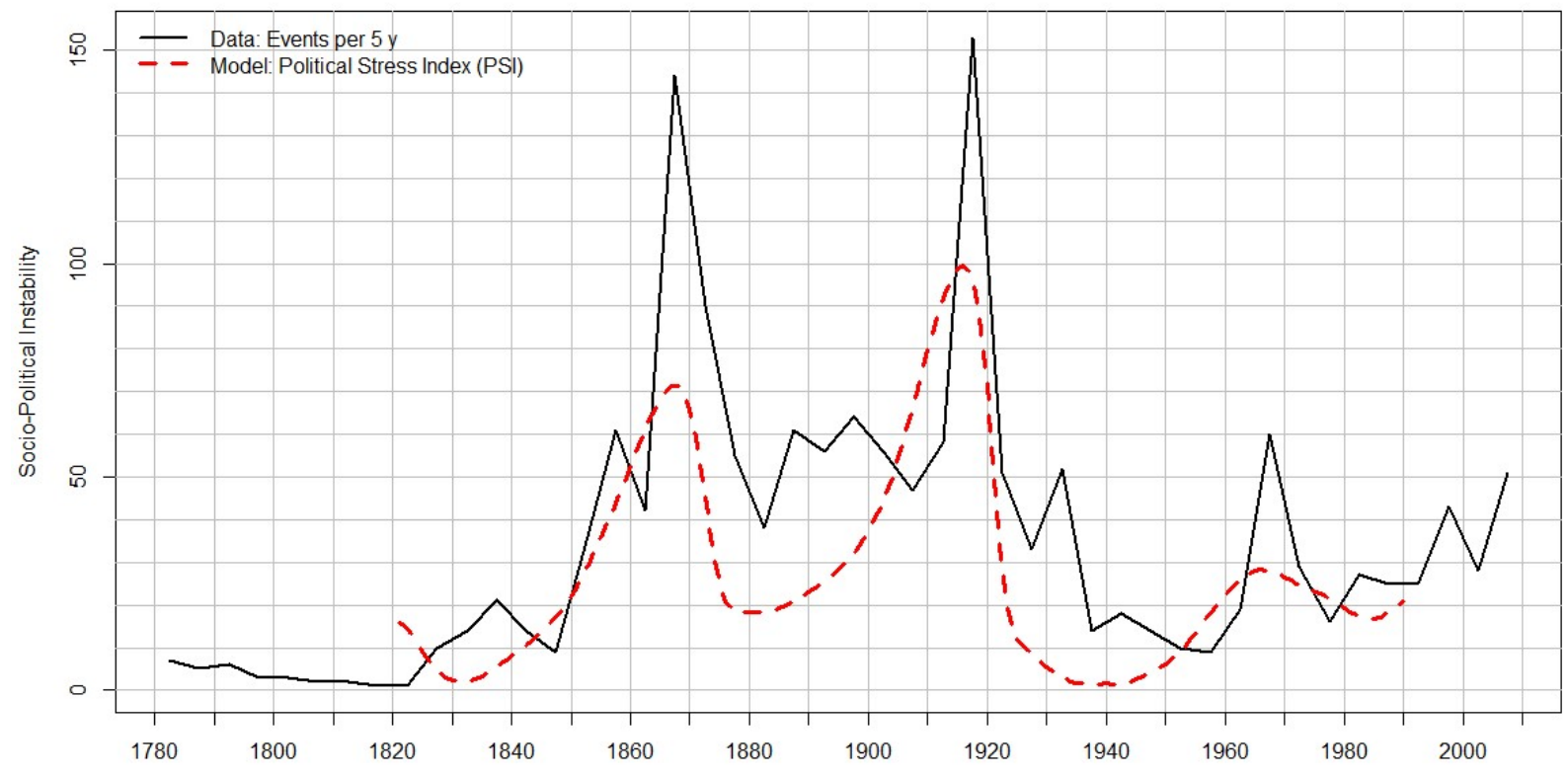

Figure 2. Temporal dynamics of sociopolitical instability in the United States. Data source (Turchin 2012); model prediction: PSI from Figure 6.

As the USPV database shows, incidence of political violence fluctuated dramatically in the US between 1780 and 2010 (Figure 2). The dynamical pattern revealed by the instability data was a secular wave with 50-year (bi-generational) cycles superimposed on it. The complete secular cycle began with a trough in 1820 and ended with another trough in 1950. In addition to this secular wave, the dynamics of instability exhibited shorter-term peaks, recurring with a period of approximately 50 years around 1870 , 1920, 1970-and now 2020.

\section{Predictor Variables: Structural-Demographic Instability Drivers}

The fundamental structural-demographic driver for instability is relative wage or, alternatively, relative income. Relative wage is defined as the wage of a "typical" worker (ideally, the median wage; but where such data are unavailable I use other proxies) divided by the GDP per capita. Relative income is defined analogously, as the median household income divided by the average household income.

To approximate the wage of typical worker I use two time series constructed by Officer and Williamson (2013b) and updated yearly: for unskilled labor and manufacturing workers. Following the approach in Turchin (2016) I index both wages to 1 in 1860, average them, and then divide the mean by GDPpc, also obtained from MeasuringWorth (Officer and Williamson 2013a). All data are in nominal US dollars. 


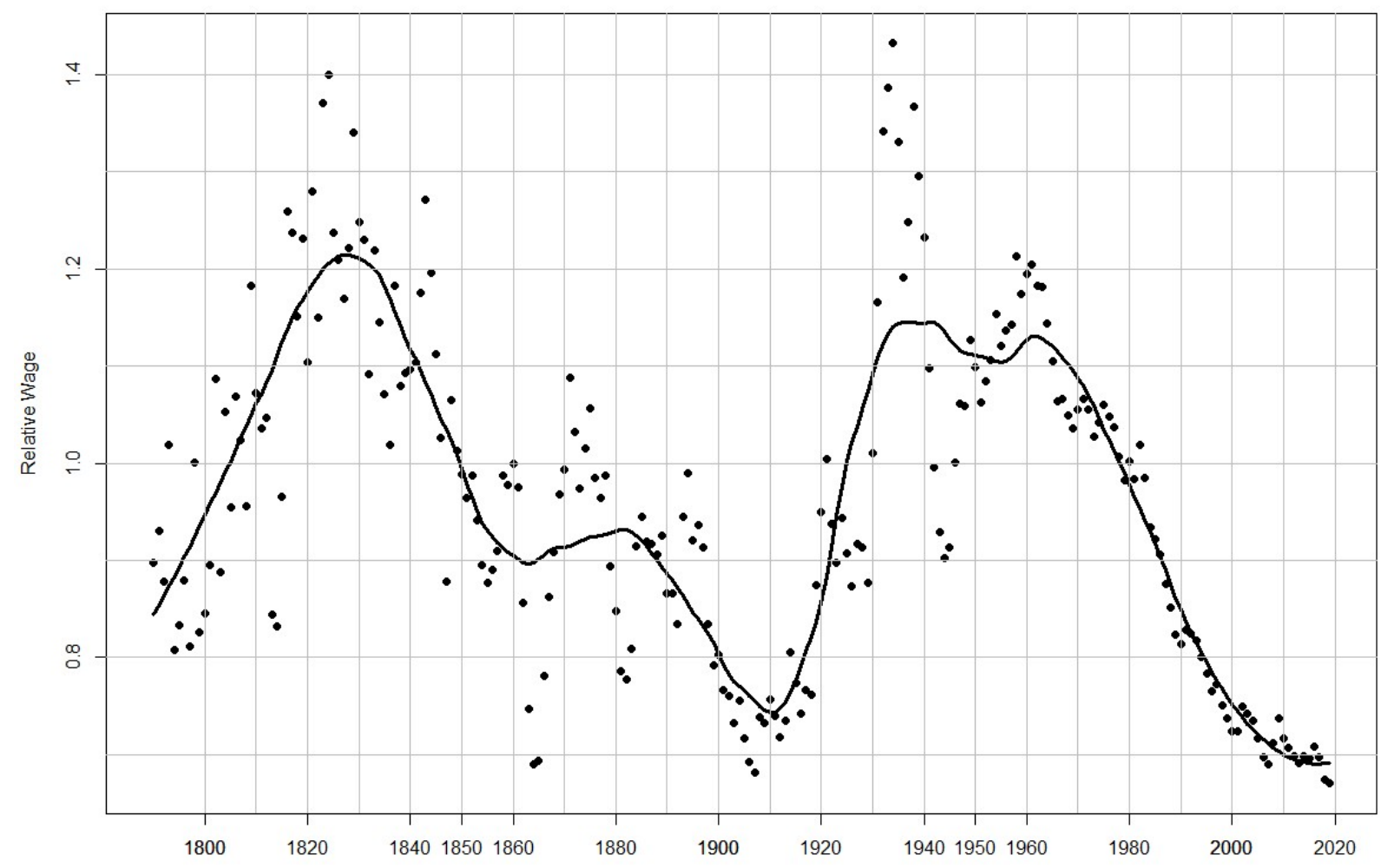

Figure 3. Temporal dynamics of relative wage in the United States, 1780-2019. The smoothed trend was obtained by LOESS.

There are two secular waves evident in these data (Figure 3). The first one peaks in 1830 and ends with a trough in 1910. The second wave has a broad peak in 1940-1960 and then declines smoothly to the present (2020).

Data on median household incomes are available only from 1945. Fortunately, there is a linear relationship between relative incomes and relative wages (Figure 4). However, the amplitude of Rellncome is smaller: it varies between 0.75 and 0.91 , where as RelWage varies between 0.69 ande 1.21 (for the same period). This effect is probably due to more members of the household joining the labor force when wages declined, as happened after 1970 in the US. 


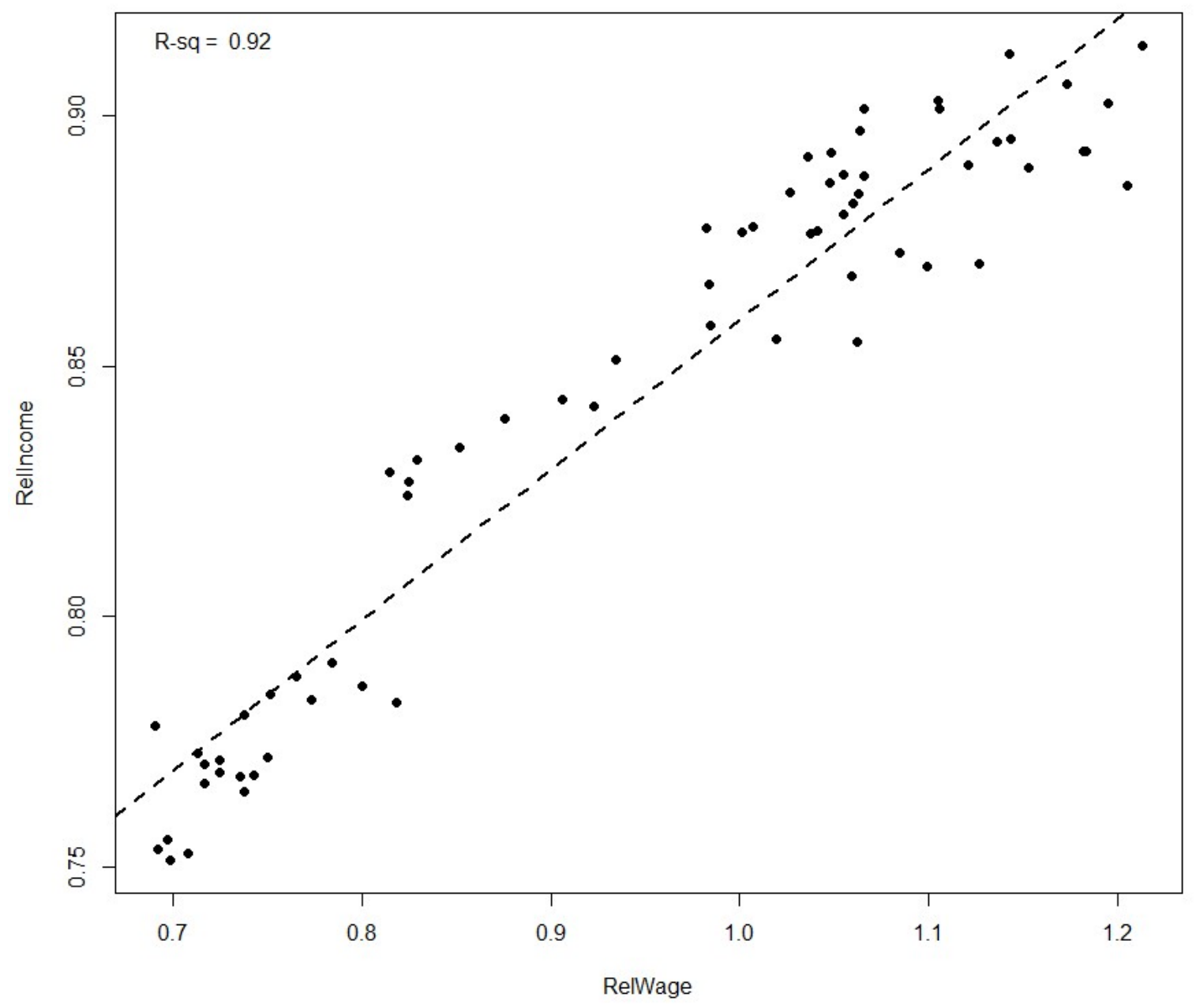

Figure 4. Relationship between Relative Income and Relative Wage.

Declining wages/household incomes are correlated with decreases in other measures of wellbeing, including biological (life expectancy, average stature) and social (age of marriage) indicators (Turchin 2016: Chapter 3). Decreasing well-being or, equivalently, growing immiseration contributes to the mass mobilization potential (MMP) of the population (Goldstone 1991), which is one of three most important SDT factors explaining socio-political unrest. Another component of MMP is a rapid growth in the number of youths. Unusually large cohorts of youths, also known as youth bulges tend to be politically destabilizing, because a sudden increase in new workers joining the labor force tends to depress their employment prospects and wages (Easterlin 1980, Macunovich 2002). Furthermore, young adults are particularly susceptible to radicalization and risk-taking. One way of capturing this driver for instability is to calculate the annual change in the relative size of the cohort aged 15-24 years (relative to the total population). These data (Figure 4) indicate that a huge youth bulge developed in the USA during the 1960s, resulting from a large "baby boomer" cohort coming of age. There were two additional youth bulges peaking during 1920 s and early 2000 s, but these were much smaller in magnitude. 


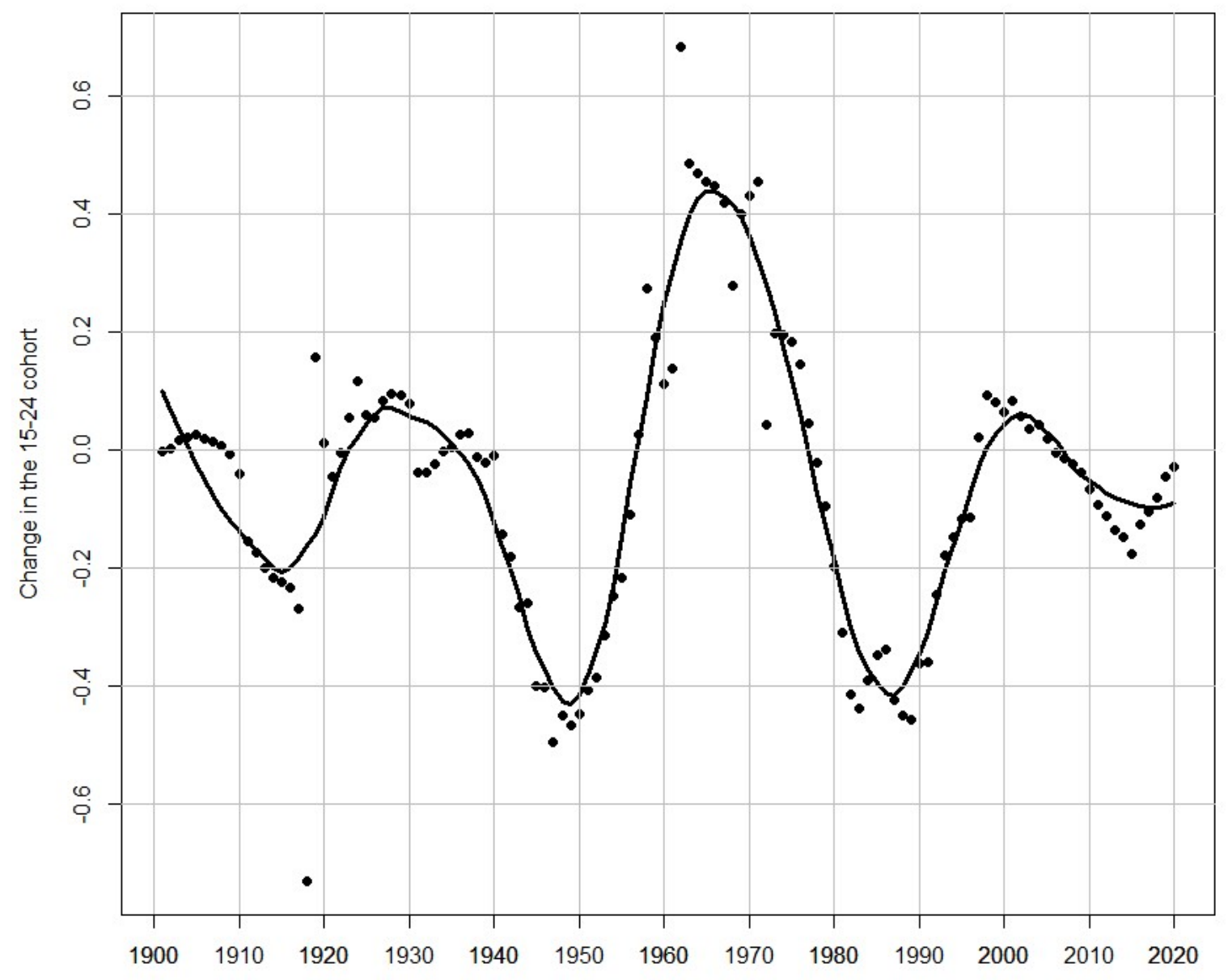

Figure 5. "Youth bulges" in the USA between 1900 and 2020. The units of change along the y-axis are percentage points (that is, the annual change in the percentage of the total population that are aged 15-24 years).

\section{Model Description}

\section{Social Contagion Module}

As noted above, the computational model at the core of the MPF engine was described in Turchin (2016: Chapter 2). The first component of it is a simple age-structured model of social contagion, inspired by the theoretical framework used in epidemiology, known as the SIR models (May and Anderson 1991). The SIR refers to the representation of the modeled population as composed of three compartments: Susceptible, Infectious, and Recovered individuals. The mathematical theory of epidemics offers a natural framework for modeling the dynamics of such cultural traits as social attitudes and norms, because individuals learn them socially, from others-just as epidemics spread as a result of people infecting each other with germs. 
There are three kinds of individual in the model. The first is the "naïve" type, corresponding to the susceptibles in the epidemiological framework. This is the class into which individuals are put when they become adults (the model tracks only individuals who are active adults; so children and the elderly beyond the retirement age are not modeled and have no effect on the dynamics). Naïve individuals can become "radicalized" by being exposed to individuals of the radical type (corresponding to infectious individuals in the SIR framework). The process of radicalization can occur as a result of encountering radicals and becoming converted to their ideology. This process of social contagion is the central feature of the module.

My primary goal here is to understand the dynamics of sociopolitical instability. The proportion of radicals in the total population is thus the key variable that we need to track. When a high proportion of the population is radicalized, sociopolitical instability should be high. Under such conditions, riots are easily triggered and readily spread, terrorist and revolutionary groups thrive and receive support from many sympathizers, and the society is highly vulnerable to an outbreak of civil war. Thus, the proportion of radicals in the population is positively related to sociopolitical instability. Note, however, that there is likely to be a nonlinear relationship between these two variables, because as the proportion of radicals in the population grows, it becomes increasingly easy for them to link up and organize, potentially leading to an accelerating effect on the levels of political violence. For reasons of parsimony, the current model does not incorporate this realistic mechanism.

A naïve individual can also become radicalized by being exposed to violence resulting from radical activities. Note that all radicals will usually not belong to a single "Radical Party". During periods of high political instability there are typically many issues dividing the population and the elites. Thus, there are many factions of radicals, warring with each other. Some become left-wing extremists, others join right-wing organizations.

The model does not track different factions of radicals, only their numbers (in proportion of the overall population). The more radicals there are, the more likely it is that a naïve individual will be exposed to political violence and become radicalized as a result. For example, someone whose relative or friend has been killed in a terrorist act perpetrated by right-wing extremists might join a left-wing revolutionary group. This second route to radicalization is also a kind of social contagion (but mediated by violence, instead of radical ideology). Both routes result in similar dynamics, so I model them with one general functional form.

The third type of individual in the model is the "moderate" (corresponding to "recovered" in the SIR framework). This group comprises former radicals who have become disenchanted with radicalism and internecine warfare, and have come to the conclusion that the society needs to pull together and overcome its differences. The moderates differ from the naïves in that they value peace and order above all, and work actively to bring it about. In other words, naïve individuals don't have an active political program, radicals work actively to increase instability, and moderates work actively to dampen it out.

Dynamical equations describing how the rates at which individuals pass into and out of the three compartments are:

$$
\begin{aligned}
& S_{a+1, t+1}=\left(1-\sigma_{t}\right) S_{a, t} \\
& I_{a+1, t+1}=\left(1-\rho_{t}\right) I_{a, t}+\sigma_{t} S_{a, t} \\
& R_{a+1, t+1}=R_{a, t}+\rho_{t} I_{a, t}
\end{aligned}
$$

The state variables are the proportions of naïve individuals in the population $(S)$, of radicals $(I)$, and of moderates ( $R$; following the SIR convention of susceptibles-infected-recovered). Subscripts refer to age $(a)$ and time $(t)$; thus, $a=1, \ldots T$ where $T$ is the maximum age (and the number of age classes). For 
example, $R_{25,1951}$, is the proportion of moderates in the age class 25 in year 1951 . "Age class $25, "$ however, does not mean that individuals within it are 25 years old. The actual age depends on when "adulthood" starts. So if the model begins to track individuals when they turn 21, age class 25 will correspond to individuals who are 45 years old.

This system of equations is simply an accounting device, keeping track of flows between different compartments. Thus, all individuals leaving the naïve compartment (at the rate $\sigma_{t}$ ) must be added to the radicalized compartment (keeping track of their age class). Similarly, all individuals leaving the radicalized compartment (at the rate $\rho_{t}$ ) are added to the moderate compartment. All the action is in the two coefficients, which are modeled as follows:

$\begin{array}{ll}\sigma_{t}=\sigma_{0}+\left(\alpha-\gamma \sum_{a} R_{a, t}\right) \sum_{a} I_{a, t} & 0 \leq \sigma_{t} \leq 1 \\ \rho_{t}=\delta \sum_{a} I_{a, t-\tau} & 0 \leq \rho_{t} \leq 1\end{array}$

The first equation says that the social contagion rate, $\sigma_{t}$, increases together with the total number of radicals ( $\Sigma I_{a, t}$, summing over all age classes). In other words, the more radicals there are, the more likely that a naïve individual becomes radicalized. However, there is an additional effect of the moderate presence: "infection" by radicalism declines as moderates increase in numbers and exert their moderating, instability-suppressing influence to reduce the probability that a naïve will become radicalized. Finally, a small fraction of naïve individuals become radicals "spontaneously," without needing to be radicalized (at the rate $\sigma_{0}$ ).

The second equation models the effect of the level of political violence on the probability of a radical becoming disgusted with radicalism and turning into a moderate. Because I proxy instability by the number of radicals, the equation for $\rho_{t}$ includes the sum of radicals in all age classes. However, note that there is a time delay, $\tau$. This parameter reflects the observation that high levels of political violence do not instantly translate into the social mood of revulsion against violence and desire for internal peace. Violence acts in a cumulative fashion; many years of high instability, or even outright civil war have to pass before the majority of the population begins to yearn for order earnestly.

In addition to the equations defining the rates of change, we also need boundary conditions. At every time step a constant fraction is added to the first age class in the naïve compartment, $S_{1, t}=1 / T$, where $T$ is the number of age classes (this ensures that the proportions of all age classes in all compartments always add up to 1). At the other end, individuals moving into age class $T+1$ are simply eliminated (they die off or retire from active political life).

Parameter $\alpha$ indicates the likelihood that an encounter between a radical and a naïve will result in the naïve becoming radicalized, while $\gamma$ measures the suppressive effect of moderates on radicalization rate. Parameter $\delta$ translates the intensity of radicalism into the rate at which radicals turn into moderates. Parameter $\tau$ measures the time scale at which exposure to violence acts to cause the backlash against it, and $T$ is the period of adult activity.

\section{Political Stress Index Module}

The second component of the model links the social contagion dynamics to the dynamics of structuraldemographic drivers for instability. We assume that $\alpha$, propensity to radicalize, is positively related to $\psi$, the Political Stress Index (PSI). When structural-demographic conditions result in high social pressure for instability, radical ideas should fall on fertile soil and readily take root and $\psi$ is high. Conversely, when pressures for instability wane, $\psi$ declines. The various structural-demographic factors that influence PSI 
are reviewed in Turchin (2016: Chapter 2). In the current implementation of the MPF engine, for reasons of parsimony, we use a stripped-down version of PSI, which tracks only three factors: immiseration (inverse relative income), age structure of the population (focusing on youth bulges), and intra-elite overproduction/over-competition (the numbers of elites in relation to the total population). The last factor assumes that the demand for elite positions is proportional to the elite numbers. The supply of such positions will grow in proportion to the total population. Thus, elite numbers relative to the total population is a measure of intra-elite competition for a limited number of positions. The equation for $\alpha(t)$ is given below (Parameterizing the Model).

\section{Elite Dynamics Module}

While immiseration and age effects are exogenous inputs into the model (this will be discussed in the next section), relative elite numbers are modeled endogenously. The calculations in this section can focus on either elite individuals and dividing them by the total population, or on counting elite households and dividing them by the total number of households. I will focus on household numbers and incomes.

Elite household numbers, $E$, can change as a result of two processes: endogenous population growth (the balance between births and deaths) and social mobility from and to the general population (with $N$ being the total number of households). Accordingly, the equation for $E$ is:

$$
\dot{E}=r E+\mu N
$$

where $r$ is per capita rate of population growth and $\mu$ is the coefficient capturing the balance of upward and downward social mobility between the general population compartment and the elite compartment of the model.

The rate of net social mobility, $\mu$, should be inversely related to the relative income, because if household incomes do not keep up with economic growth, the elites dispose of an increasingly large amount of surplus. A favorable economic conjuncture for employers, thus, creates greater upward mobility opportunities for entrepreneurial commoners. I assume that

$\mu=\mu_{0}\left(\frac{w_{0}}{w}-1\right)$

where $w$ is the relative income and $\mu_{0}$ and $w_{0}$ are scaling parameters. Parameter $\mu_{0}$ modulates the magnitude of response in social mobility to the availability of surplus. Parameter $w_{0}$ is the level at which there is no net upward mobility (when $w=w_{0}, \mu=0$ ). The more $w$ falls below that level, the more positive the term on the right hand side will be, and the more vigorous upward social mobility. Conversely, when $w$ increases above $w_{0}$, upward social mobility is choked off, and the net mobility is downwards (out of the elite compartment into the general population).

Combining these two equations, we have the following model for the dynamics of elite households:

$$
\dot{E}=r E+\mu_{0}\left(\frac{w_{0}-w}{w}\right) N
$$

If the demographic rate of elite increase is the same as that characterizing the general population, then this equation can be simplified by focusing on relative elite numbers, $e=E / N$. After some algebra we have

$\dot{e}=\mu_{0} \frac{w_{0}-w}{w}$ 
In other words, if the elites do not differ in their demography from commoners, the rate of change of relative elite numbers is simply the net rate of social mobility.

It is also useful to add to the model a calculation of how the average elite income changes with time. I will assume that the elites divide among themselves the amount of surplus produced by the economy. This surplus is $G-W N$, where $G$ is the total GDP, $W$ is the (commoner) household income (not scaled by GDPpc), and $N$ is the number of households.

Dividing this quantity by the elite numbers $(E)$ we obtain average surplus per elite. Finally, we scale average surplus per elite by the GDP per household $(g=G / N)$, or relative elite income:

$\varepsilon=\frac{1}{g} \frac{G-W N}{E}$

which simplifies to

$\varepsilon=\frac{1-w}{e}$

where $w$ is the relative commoner income and $e$ is relative elite numbers (elites as a proportion of the total population).

So far the elite module has focused on upward social mobility-processes resulting in the expansion of the elite numbers. However, expansion cannot go forever. Analysis of historical secular cycles (Turchin and Nefedov 2009, Turchin 2016) indicates that periods of downward social mobility from the elites into the commoner class are strongly associated with disintegrative phases, or "Ages of Discord." Political instability and internal warfare prune elite numbers in a variety ways. Some elite individuals are simply killed in civil wars or as a result of assassination. Others may be dispossessed of their elite status by their faction losing in civil war. Finally, general conditions of violence and lack of success discourages many of the "surplus" elite aspirants from continuing to purse elite status, as a result of which they accept downward mobility.

A parsimonious way to model this process is by adding another term to the elite equation as follows:

$\dot{e}=\mu_{0} \frac{w_{0}-w}{w}-\left(e_{t}-e_{0}\right) R$

here $\left(e_{t}-e_{0}\right)$ are the surplus elites (elite exceeding the level for whom elite positions are available $e_{0}$ ) and $R$ is the proportion of the population that has converted from radicals to moderates. In other words, the assumption here is that surplus elites are first radicalized and then make the transition from radicals to moderates, in the process accepting non-elite status.

\section{Parameterizing the Model}

The fundamental driver of the dynamics in the model is the trajectory of relative income, $w(t)$. As we saw above, $w$ varies between 0.91 and 0.75 . I will assume that the level at which upward social mobility is zero, $w_{0}=0.9$, near the upper limit of observed $w$ values. This assumption implies that when the social system is in equilibrium (that is, relative elite numbers are neither increasing, nor decreasing), $90 \%$ of GDP goes to commoner households and $10 \%$ goes to elite households. Further assuming a conventional level for the relative elite numbers at this equilibrium, $e_{0}$, as 0.01 (the proverbial 1 percent), we have the mean elite income as $0.1 / 0.01=10$, or an order of magnitude greater than $w_{0}$. Note, however, that once the social system leaves the equilibrium, both relative elite numbers and their average incomes will change dynamically.

When relative incomes decline below $w_{0}$, elite numbers start increasing. The rate of increase is governed by the parameter $\mu$, which I set to 0.3 because it results in $2-3$ fold increase in elite numbers 
over 30 years, which is what happened both in the run up to Civil War (Turchin 2016: Table 8.1) and between 1980 and 2010 (Turchin 2016: Table 13.1).

Parameters of the social contagion module were the same as used previously (Turchin 2016: caption of Figure 2.3): $\gamma=1, \delta=0.5, \tau=10$, and $T=35$. The key link between the social contagion and structural-demographic models is the parameter $\alpha$ (propensity to radicalize). As stated above, the model tracks three factors: immiseration (inverse relative income), age structure of the population (with the focus on youth bulges), and intraelite overproduction/overcompetition (the numbers of elites in relation to the total population). I used the following formula:

$\alpha(t)=\alpha_{0}+\alpha_{w}\left(w_{0}-w\right)+\alpha_{e}\left(e-e_{0}\right)+A_{20}$

where $\alpha_{0}=0.1$ is the base level, $\alpha_{\mathrm{w}}=1$ is the weight given immiseration, and $\alpha_{\mathrm{e}}=0.5$ is the weight given elite overproduction. the elite component weight is lower than that for immiseration because whereas the immiseration factor changed between 0 and 0.25 , the elite factor changes with a greater amplitude, between 0 and 1 . The youth bulge effect, $A_{20}$, was modeled as a single perturbation using a Gaussian functional form centered on 1965 with standard deviation of 10 years and the peak value of 0.2 .

\section{Testing the MPF Engine with Historical Data}

This section describes model dynamics for the period between 1810 and 1990. Because model parameters were selected based on historical data and to match model behavior with instability data during this time period, this is not a formal test of model accuracy. Rather, it is a test of whether model is capable of generating historically observed dynamics for plausible values of parameters. We can think of the period 1810-1990 as the "training set" for the model, and the subsequent period (see next section) as the "prediction set" (especially the period after 2010, which constitutes a formal test of model predictions published in 2010).

As Figure 2 shows, relative wage decreased between 1830 and 1860. Using the relationship between relative wages and relative incomes (Figure 4), we can assume that relative income, $w$, decreased from the equilibrium value of 0.9 to roughly 0.75 . The first scenario that we examine is the effect of this decrease on the model-generated dynamics (Figure 6). Using the dynamics of $I$ (proportion of population that is radicalized, summing over all age classes, red curve in the figure) as a proxy for socio-political instability, we observe that the decline in $w$ generates a rapid increase in $e$ (relative elite numbers). Decline in $w$ and increase in $e$ translate into higher PSI and, therefore, growing propensity to radicalize ( $\alpha$, green dashed curve). This is followed by a spike in / that peaks during the early $1860 \mathrm{~s}$ (corresponding to the American Civil War). However, high I and associated political turbulence results in increasing $R$ (the proportion of moderates), which eventually suppresses the violence wave. At the same time, violence reduces the elite numbers. Historically, this was a result of two processes. First, a high proportion of the Antebellum ruling class (slave-owning southerners) was killed in the Civil War battles. Second, and quantitatively even more important, was the freeing the slaves, which destroyed the wealth of the Antebellum southern elites and eliminated them as national elites for decades to come. They were replaced by a northern elite, whose wealth was based on free labor and industrialization.

However, the release of social pressures resulting from the destruction of the Antebellum elites was short-lived. Because relative incomes stayed at the low level, the pump transferring wealth from workers to employers continued to operate and by the early 1900s elite overproduction reached and exceeded the 1860 level. In the absence of action that would stop the pump, the model predicts, the USA were doomed to experience a series of increasingly violent crises during the 1910s, then 1960s, and beyond, recurring at roughly 50 year intervals. As indicated by increasing peaks in $\alpha$ (green dashed curve), each subsequent crisis would strain the fabric of the American society ever more. Furthermore, 
although PSI would decrease following each bout of downward mobility, even between peaks it stayed at an elevated level, compared to where it was during the Era of Good Feelings c.1820.

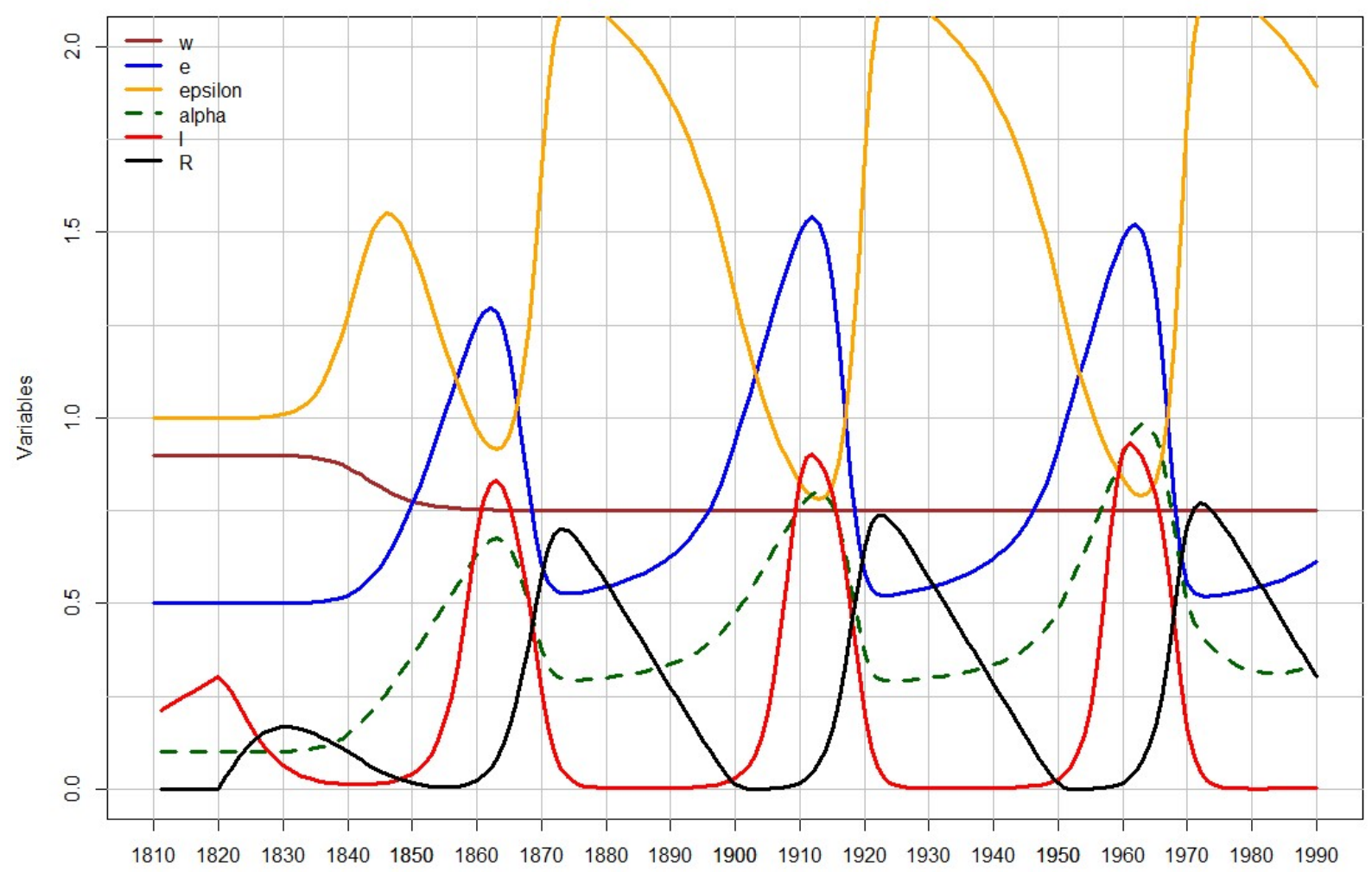

Figure 6. Model-generated dynamics assuming a single decline in $w$ between 1830 and 1860.

Fortunately, this is not what happened. Instead, the American elites, increasingly frightened by the continuing social turbulence and political violence, implemented a series of reforms during the first third of the twentieth century (for details, see Turchin 2016: Chapter 10 and Hoyer et al., forthcoming). A major result of these reforms was that between 1910 and $1940 w$ returned to $w_{0}$. Implementing this change in the model, we see the following dynamics (Figure 7). The 1910s instability peak is very little affected, but the return of the relative income to the equilibrium level shuts down the pump. As a result, once the surplus elites are eliminated, the elite numbers stay near the equilibrium levels. The PSI declines to another low by 1950 , as it did in real history.

There is still a radicalization peak in the 1970s, but its magnitude is much lower than the 1910s peak. The 1970 s peak is due to a combination of factors: first, the fathers-and-sons dynamics (the moderating memory of the previous instability peak fades by 1950, as indicated by $R$ reaching zero) and, second, the effect of the 1960s youth bulge. 


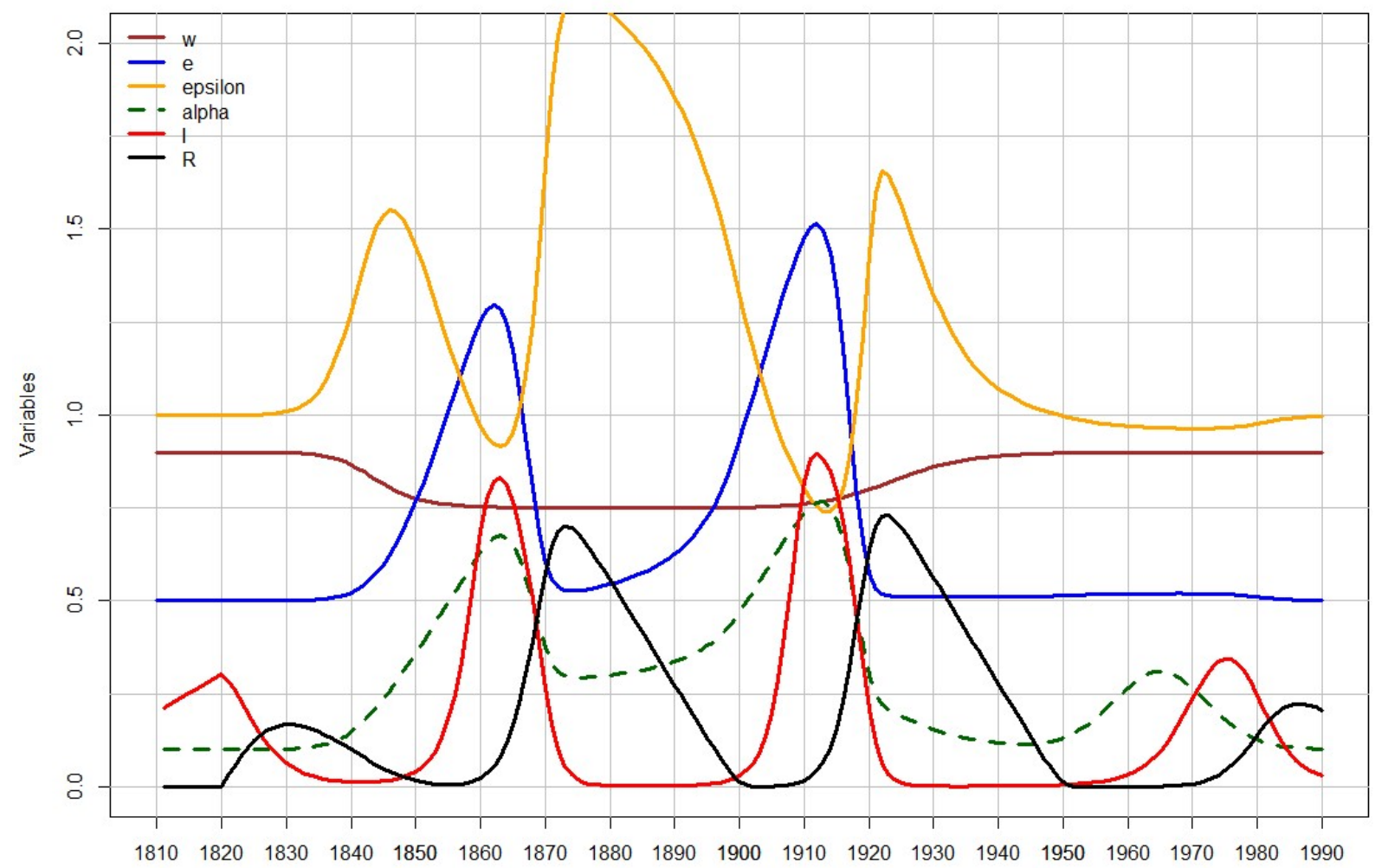

Figure 7. Model-generated dynamics assuming that a decline in $w$ between 1830 and 1860 is followed by an increase between 1910 and 1940 .

\section{Using the MPF Engine for Forecasting Future Trajectories}

I now use the MPF engine to investigate the possible trajectories that the American social system could take beyond 2020. The only parameter change I introduce is an increase in $T$ (the length of active adult life) from 35 to 45 . Whereas for the past (and especially for the nineteenth century) it made sense to assume that adults are active between 20 and 55 years of age, increased life expectancy today suggest that this period should be lengthened to 20-65.

As in previous section, I start with a single transition, this time taking place between 1970 and 2000 (Figure 8). As before, the decline in $w$ turns on the pump, and elite numbers begin to increase in an accelerating manner. The moderating effect of the previous (mild) peak of instability in the 1970s fades away by the early 2000s (the black curve). This releases a spike of radicalization, which should peak during the 2020s. Note that all dynamics have been well set before the 2010 forecast of future instability. In fact, the dynamics are set as soon as $w$ finishes its transition. If nothing is done to bring $w$ back up to its equilibrium level, we will see a temporary lull, with PSI declining somewhat (but not to its equilibrium level). As the pump would continue operating, another spike of violence would inevitably come, peaking in the late 2070s. In other words, we will have a repeat of the 1860s-1920s Age of Discord with two spikes about 50 years apart. 


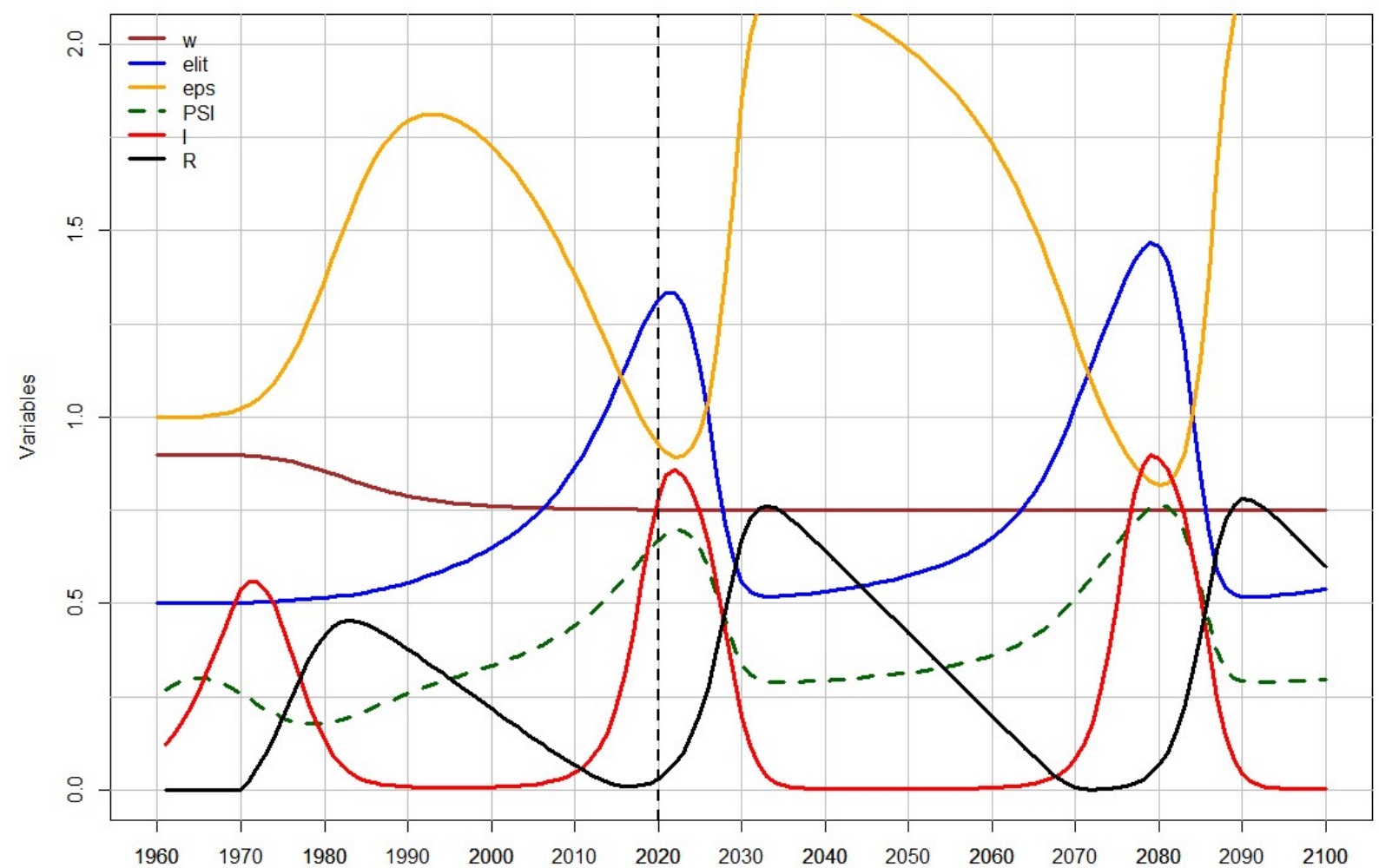

Figure 8. Model-generated dynamics assuming that a single decline in $w$ between 1970 and 2000.

Let us now see what happens if action is taken to bring $w$ back to $w_{0}$. Assuming (somewhat unrealistically) the most favorable scenario, $w$ is brought up between 2020 and 2025 (Figure 9). This intervention will not eliminate, or even have much of an effect on the 2020s peak-there is too much inertia in the social system. Furthermore, it will result in a significant negative effect on the average elite incomes (notice the orange curve dipping down well below the equilibrium level of 1). Such relative impoverishment of the elites is likely to exacerbate the crisis. However, after a painful and violent decade of the 2020 s the system will rapidly achieve its equilibrium. PSI will reach its minimum, the proportion of the population that is radicalized will fall, and the surplus elites will be eliminated. The only memory of the Troubles of the 2020 s will be in a high proportion of moderates, who will gradually fade away towards 2070 . The end result will be "sharp short-term pain-long-term gain" outcome.

The MPF engine can be used to explore other scenarios. For example, Figure 10 shows what would happen if the increase in $w$ is more gradual. In this case, there is even a short-lived spike in average elite incomes. However, the process of equilibration still requires that the surplus elites are eliminated, one way or another. 


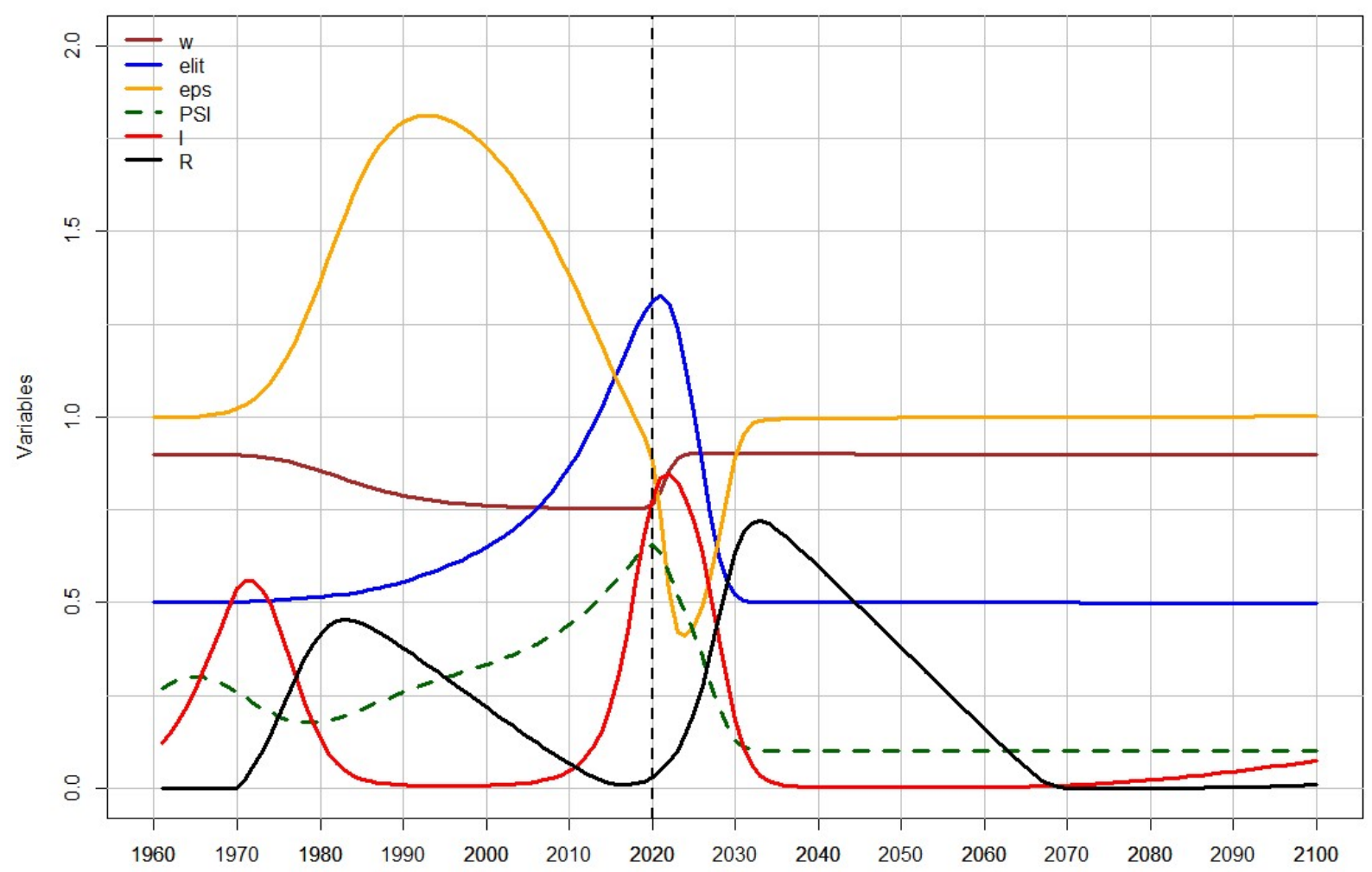

Figure 9. Model-generated dynamics in which a decline in $w$ between 1970 and 2000 is followed by a rapid increase in the 2020 s. 


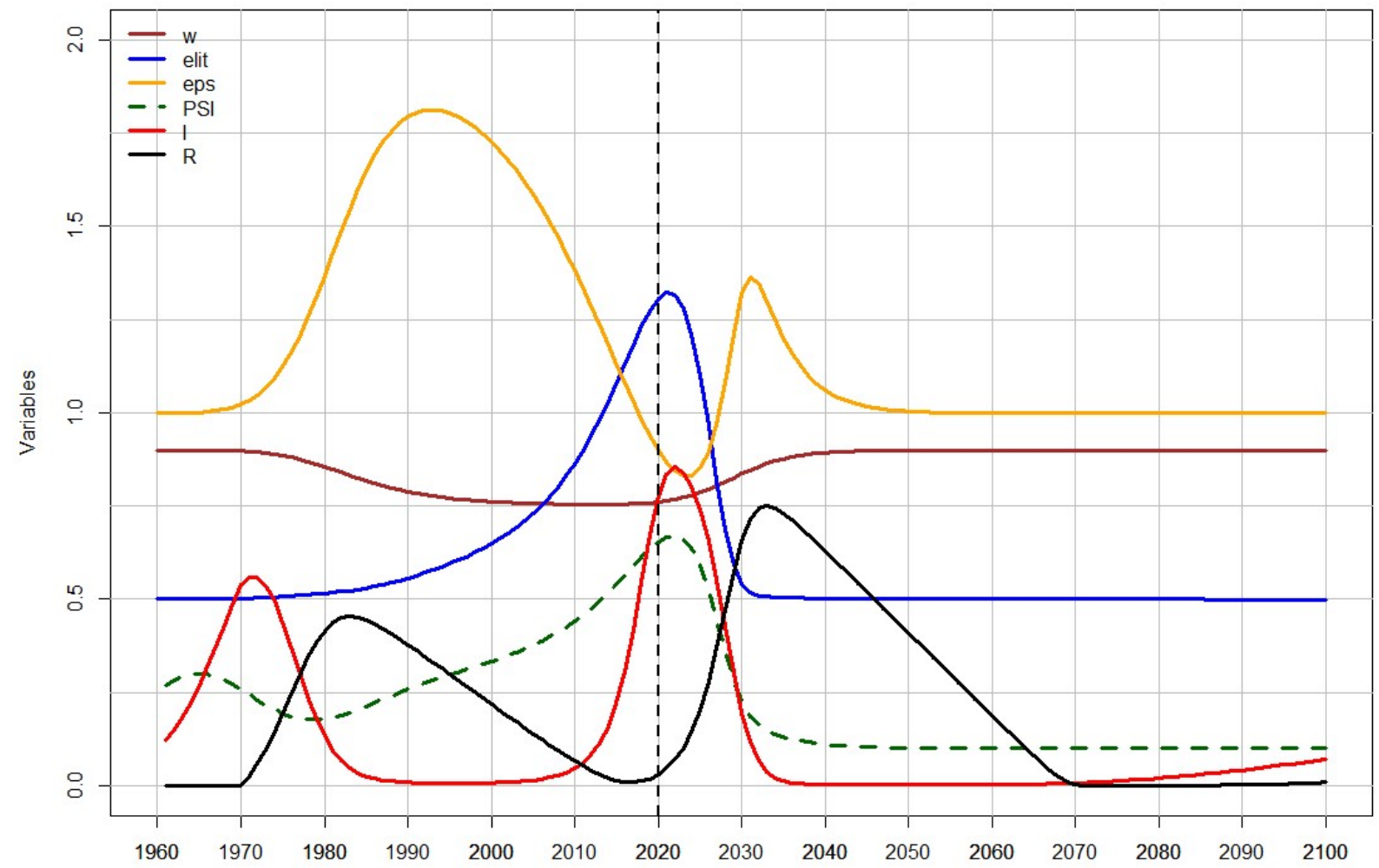

Figure 10. The "slow decrease" scenario.

\section{Conclusion}

The ability of the "prototype" MPF model to reproduce the key aspects of the historical instability trajectory in the US between 1810 and 1990 and, especially, the success of the 2010 forecast for 2020, are encouraging and support the overall feasibility of building a fuller version. However, I emphasize that this is an MPF prototype, not a fully developed product. Most importantly, we have not yet built in the prototype the ability for ensemble forecasts, in which the model is run repeatedly while affected by different sequences of stochastic perturbations. This feature will enable us to see how much uncertainty is associated with the model predictions. Furthermore, MPF is a nonlinear dynamic model, and thus it is likely that in some parts of the phase space the prediction will be affected by rapid trajectory divergence, while in others by slower divergence or even convergence.

Second, the MPF forecasts in the prototype assume that parameter values are fixed, whereas in reality they are always estimated with some error. We need to translate this source of uncertainty into the predictions.

Third, and at a more general level, we need to investigate how including (or not) different mechanisms into the model affects its predicted dynamics. Related to this, a single success, as we saw with the 2020 prediction, could always be due simply to chance. It is imperative to replicate this case study for many more societies entering crisis and exiting from it. Such an effort is currently under way by the Seshat project, which is building a CrisisDB that will include several hundreds of past societies sliding 
into crises and then out of it. In particular, we are going to quantify the characteristics of several collapses discussed in this volume.

Overall, we are just starting on the road that would eventually yield a useable MPF engine. But it is already clear that this is a highly fruitful avenue of future research with potentially huge consequences for keeping our complex societies from collapse.

Acknowledgement. I thank the participants of the working group at the Complexity Science Hub on Social Complexity and Collapse: Nina Witoszek, Stefan Thurner, David Garcia, Roger Griffin, Daniel Hoyer, Atle Midttun, James Bennett, Knut Myrum Næss, and Sergey Gavrilets. Daniel Hoyer provided helpful comments on a draft of this article. This research has been supported by CSH Vienna (the Austrian Research Promotion Agency FFG projects \#857136 and \#873927) and V. Kann Rasmussen Foundation.

\section{References}

Butzer, K. W., and G. H. Endfield. 2012. Critical perspectives on historical collapse. PNAS 109:3628-3631.

Casti, J. L. 2012. X-Events: Complexity Overload and the Collaps of Everything. William Morrow, New York.

Cumming, G. S., and G. D. Peterson. 2017. Unifying Research on Social-Ecological Resilience and Collapse. Trends in Ecology \& Evolution 32:695-713.

Diamond, J. 2004. Collapse: How Societies Choose to Fail or Succeed. Viking, New York.

Easterlin, R. 1980. Birth and Fortune. Basic Books, New York.

Gilje, P. A. 1996. Rioting in America. Indiana University Press, Bloomington, IN.

Goldstone, J. A. 1991. Revolution and Rebellion in the Early Modern World. University of California Press, Berkeley, CA.

Grimstead, D. 1998. American Mobbing, 1828-1861: Towards Civil War. Oxford University Press, New York.

Korotayev, A., and D. Khaltourina. 2006. Introduction to Social Macrodynamics: Secular Cycles and Millennial Trends in Africa. URSS, Moscow.

Korotayev, A., J. Zinkina, S. Kobzeva, J. Bozhevolnov, D. Khaltourina, A. Malkov, and S. Malkov. 2011. A Trap at the Escape from the Trap? Demographic-Structural Factors of Political Instability in Modern Africa and West Asia. Cliodynamics 2:276-303.

Macunovich, D. J. 2002. Birth Quake: The Baby Boom and Its Aftershocks. Universtiy of Chicago Press, Chicago.

May, R. M., and R. M. Anderson. 1991. Infectious diseases of humans: dynamics and control. Oxford University Press, Oxford.

Nefedov, S. 2002. On the theory of demographic cycles (in Russian). Ekonomicheskaya Istoriya 8:116121.

Nefedov, S. А. 2005. Нефедов С. А. Демографически-структурный анализ социально-экономической истории России. Екатеринбург, 2005.

Nefedov, S. A. 2009. War and Society (In Russian: Voyna i obschestvo. Faktornyi analiz istoricheskogo protsessa). Publishing House "Territoriya buduschego", Moscow.

Officer, L. H., and S. H. Williamson. 2013a. The Annual Consumer Price Index for the United States, 17742012. MeasuringWorth. URL: http://www.measuringworth.com/uscpi/

Officer, L. H., and S. H. Williamson. 2013b. Annual Wages in the United States, 1774-Present. MeasuringWorth. URL: http://www.measuringworth.com/uswages/.

Renfrew, C. 1984. Approaches to Social Archaeology. Cambridge University Press, Cambridge, MA. Tainter, J. A. 1988. The Collapse of Complex Societies. Cambridge University Press, Cambridge, UK. 
Tainter, J. A. 1995. Sustainability of complex societies. Futures 27:397-407.

Toynbee, A. J. 1957. A study of history. Volume II. Oxford University Press, London.

Turchin, P. 2003. Historical dynamics: why states rise and fall. Princeton University Press, Princeton, NJ.

Turchin, P. 2010. 2020: Political Instability May Play a Role. Nature 463:608.

Turchin, P. 2012. Dynamics of Political Instability in the United States, 1780-2010. Journal of Peace Research 4:577-591.

Turchin, P. 2013. Modeling Social Pressures Toward Political Instability. Cliodynamics 4:241-280.

Turchin, P. 2016. Ages of Discord: A Structural-Demographic Analysis of American History. Beresta Books, Chaplin, CT.

Turchin, P., and A. Korotayev. 2020. The 2010 structural-demographic forecast for the 2010-2020 decade: A retrospective assessment. PLOS ONE 15:e0237458.

Turchin, P., and S. Nefedov. 2009. Secular Cycles. Princeton University Press, Princeton, NJ.

Turchin, P., N. Witoszek, S. Thurner, D. Garcia, R. Griffin, D. Hoyer, A. Midttun, J. Bennett, K. Myrum Næss, and S. Gavrilets. 2018. A History of Possible Futures: Multipath Forecasting of Social Breakdown, Recovery, and Resilience. Cliodynamics 9:124-139.

Weiss, H., and R. S. Bradley. 2001. What Drives Societal Collapse? Science 291:609-610. 